\title{
Historia y neutralidad ideológica. Valores, posiciones políticas y ética de la investigación
}

\author{
History and ideological neutrality. Values, \\ political positions and ethics of research
}

ÁLVARO CASTRO SÁNCHEZ ${ }^{1}$ (Universidad de Córdoba)

Artículo recibido: 2 de abril de 2021

Solicitud de revisión: 15 de mayo de 2021

Artículo aceptado: 9 de noviembre de 2021

Castro Sánchez, Álvaro (2022). Historia y neutralidad ideológica. Valores, posiciones políticas y ética de la investigación. Recerca. Revista de Pensament $i$ Análisi, 27(2), pp. 12o. doi: http://dx.doi.org/10.6035/recerca. 5856

\section{Resumen}

El presente trabajo plantea un modelo de análisis de las relaciones entre objetividad e ideología política desde una ética de la investigación histórica. Tomando por caso un reciente debate acerca de las elecciones españolas de febrero de 1936 y sus interpretaciones, se plantea la imposibilidad de separar la subjetividad de la objetividad y de apagar el sujeto político, tanto desde la hermenéutica filosófica como desde la epistemología de las ciencias sociales. Sin caer por ello en el relativismo, se plantean posibles caminos para un trabajo historiográfico ético, reclamando la necesidad de este tipo de estudios desde el ámbito propio de la filosofía práctica.

Palabras clave: ideología, historiografía, ética de la investigación social.

\section{Abstract}

This paper outlines an analytical model for relations between objectivity and political ideology from an ethically sound historical research standpoint. With a recent public debate on the interpretations of the 1936 Spanish general elections as a case study, this paper lays out the impossibility of separating subjectivity from objectivity and disempowering the political subject, from both a Philosophical Hermeneutics and an Epistemology of Social Science viewpoint. Relativism is avoided in spite of this approach, and possible route plans

${ }^{1}$ z52casaa@uco.es 
for an ethically sound historiographical research, while claiming the need for those studies within the scope of Moral Philosophy.

Key Words: ideology, historiography, ethics of social research.

\section{INTRODUCCIÓN}

La investigación acerca de la ética del oficio historiador o, más en concreto, lo que vendría a ser una ética de la investigación en historia es un ámbito poco explorado desde el campo de la filosofía práctica española, aunque los historiadores han escrito y debatido de forma frecuente respecto a problemáticas de esa índole. Dicho vacío en la filosofía moral continental contrasta con el magnífico desarrollo que en las últimas décadas han tenido la ética de la investigación en ciencias naturales, la bioética o la ética ecológica.

Ha sido en la tradición anglosajona donde se ha atendido de forma más específica la ética del trabajo historiográfico (Beauchamp, Faden, Wallace y Walters, 1982; Lahman, 2018; McIntyre y Clark, 2004; Wiener, 2005). En el volumen colectivo The Ethics of History (Carr, Thomas y Makkreel, 2004) se plantean algunas de las preguntas que atañen de forma específica a la ética y la responsabilidad social que le conciernen: sobre el escrutinio ético de la metodología, la relación entre valores morales y estilo narrativo, entre epistemología y ética de la investigación, entre verdad y deber moral, la apelación de las vidas del pasado a la sociedad presente y cómo nos conciernen moralmente (justicia, reparaciones, etc.), los contornos de la responsabilidad profesional o la relación entre ideas políticas, temática elegida, objetividad y producción de conocimiento histórico, etc. Todas ellas son cuestiones fundamentales para tener en cuenta de cara a las buenas prácticas del oficio de investigación y transferencia científicas en ese terreno. Para evitar que las declaraciones de tipo ético, como a veces ocurre con los códigos deontológicos, se queden en meras muestras de intenciones o no promuevan la asimilación de normas y valores, debe de partirse de la práctica investigadora real.

Dicho esto, las tensiones en términos morales parece que se incrementan conforme más se acercan los acontecimientos o procesos que se estudian, más abiertos permanecen y más traumáticos fueron estos socialmente hablando. Especialmente en estos casos, hay dilemas morales que se presentan directamente en el trabajo de investigación con fuentes primarias $\mathfrak{u}$ orales. ¿Cuáles son los límites de la intimidad, de la privacidad o del derecho al honor familiar cuando, por ejemplo, aparecen cartas privadas confiscadas por autoridades, 
nombres y apellidos de represores o declaraciones que delatan a otros vecinos investigando los procesos de guerra o represión? ¿Hay que dar los nombres de los victimarios o colaboradores? En otra dirección, ¿no hay implicaciones morales en términos de paternalismo, por ejemplo, en la intervención de especialistas en historia - no digamos ya del Estado- en la memoria de la comunidad? ¿Qué ocurre también con la tergiversación o mal uso de las fuentes de forma consciente o inconsciente? Además, la tarea historiadora puede ir más allá de la del narrador veraz del pasado, pues también en ámbitos como el de la historia del presente - aquella de la que quedan supervivientes en la actualidad y que se suele cifrar a partir de 1945 - se puede ser llamado como perito o testigo experto por las instituciones de justicia (Allier, 2011: 151-171).

Por lo tanto, nos podemos plantear en qué sentido se puede constituir la problemática moral derivada de la investigación y la narración histórica como objeto específico de estudio por parte de la ética aplicada. ¿Contribuiría la reflexión filosófica a no solo orientar la labor de los historiadores sino también a enriquecer su actividad desde un punto de vista epistemológico? Estas son las preguntas que abren este trabajo, que se va a centrar en una cuestión debatida dentro del campo historiográfico y de relevancia pública: la de la relación entre valores, neutralidad y objetividad científicas, en un momento en el que la polarización política de la historia se ha vuelto persistente.

Se va a tratar de defender la imposibilidad de anular el sujeto político por parte de quien investiga y narra unos acontecimientos históricos. La dificultad de separar lo subjetivo de lo objetivo y, más en particular, la ideología de la investigación cuenta con un amplio debate filosófico e historiográfico. Por acotar el estudio, entenderemos ideología como ideología política y no como conjunto de ideas o representaciones acerca del mundo, etc. Mientras que, sin poder entrar tampoco en el largo debate en torno a la teoría de la referencia o de la verdad, entenderemos como objetividad la pretensión realista del acceso a un objeto de estudio libre de influencias respecto a las posiciones o predisposiciones del sujeto que lo aborda.

Aquí se defenderá que la parcialidad no está reñida ni con la objetividad ni con el desarrollo de la excelencia profesional. Dada la inabarcable literatura al respecto generada en el ámbito de la historiografía, se tomará un caso de estudio concreto: el de las recientes interpretaciones sobre la victoria electoral del Frente Popular en las elecciones de febrero de 1936. Aun así, aquí solamente habrá espacio para apuntar algunas líneas de reflexión que se ampliarán en otros trabajos. 


\section{POSICIÓN POLÍTICA Y OBJETIVIDAD HISTÓRICA}

Los últimos años del influyente historiador Josep Fontana (fallecido en el 2018) estuvieron marcados por las críticas que recibió por su apoyo manifiesto a la candidatura de Ada Colau a la alcaldía de Barcelona en el 2015 y por su reivindicación de la existencia de los catalanes como comunidad diferenciada de la de los españoles en obras como La formació d'una identitat. Una história de Catalunya (2014). ${ }^{2}$ Años antes, en el 2012, la muerte de Eric Hobsbawm también provocó debate acerca de la valía de la obra de un historiador que se declaró abiertamente marxista y que solo tardíamente habría criticado el estalinismo. ¿Restaba ello valor a su legado intelectual?

El problema que nos planteamos con estos ejemplos concierne a la calidad científica de quienes no esconden sus afinidades políticas, sobre lo cual no hay consenso en el gremio. Así, en las páginas de Cultura del diario $A B C$ apareció una encuesta firmada por Tulio Demicheli (2012) en la que José Álvarez Junco señalaba, a propósito de Hobsbawm, que no es posible ser objetivo cuando se escribe sobre temas humanísticos pero que ello no implica necesariamente arbitrariedad. La honestidad reside en la no deformación de las fuentes y en la no ignorancia o marginación de aquellos datos o informaciones que no gustan. Por su parte Juan Pablo Fusi recuperaba en la misma página la figura de Leopold von Ranke, fundador de la ciencia histórica, y su llamada a la objetividad, la exhaustividad y la mesura narrativa. Pero si la historia como ciencia racional que rompía con la propensión a la mitomanía anterior fue establecida por la escuela histórica alemana que encabezó Ranke, sus postulados parecen contradichos por trayectorias de enorme éxito editorial y de respeto historiográfico como las de Hobsbawm o el propio Fontana.

La ciencia histórica surgió como resultado de un maridaje de la tradición literaria o narrativa anterior con la erudición documental, lo que vendría a suplantar la mera crónica de hechos pasados (Moradiellos, 1994: 31-37). Ranke, profesor en la Universidad de Berlín que elaboró una ingente obra sobre historia política y diplomática de Europa, declaró que su trabajo consistía en mostrar con transparencia lo que realmente sucedió. Ello se interpretó como que el uso racional y contrastado de las fuentes conllevaría la anulación de la subjetividad de un investigador, que se convertiría en notario del pasado y se limitaría a transmitir lo que ocurrió libre de valoraciones y juicios personales. Tal

\footnotetext{
${ }^{2}$ Entre ellas, por apuntar algunas, fueron duras las palabras de Gabriel Tortella (2015), así como las de Santos Juliá (2015) o la réplica en forma de libro de Jordi Canal (2015).
} 
postura, de inspiración empirista, daría lugar a lo que se llamó historicismo. Frente al influjo del idealismo hegeliano dominante en la universidad alemana, se reivindicaba la radical historicidad de los fenómenos humanos, los cuales deben interpretarse en su concreción y no en base a leyes universales que trascienden la singularidad de los hechos históricos. Así, el material fundamental de la tarea historiadora radica en las fuentes primarias y la investigación archivística es la medida de todo buen profesional. Sin embargo, el desarrollo de la ciencia histórica durante el siglo y medio que le siguió parece más bien demostrar la imposibilidad de eliminar los valores del proceso interpretativo de las fuentes y de construcción del relato histórico.

Como puso de relieve el propio Fontana, la escuela de Ranke no estaba libre de motivaciones políticas e ideológicas al desarrollarse esta en el curso de la construcción del Estado alemán. Toda historia ha tenido siempre una función social, se enmascare esta o no, desde antes incluso de la escritura, defendió Fontana en su clásico Historia. Análisis del pasado y proyecto social (1982). Ranke tuvo su mejor público en las élites prusianas que le abrieron las puertas de la universidad y lo pusieron en la dirección de la conservadora Revista Histórico Política. Pero su famosa aseveración acerca de contar las cosas como sucedieron ha sido objeto de un equívoco, pues el alemán decía que la misión del historiador era no solo recopilar datos, sino comprenderlos y explicarlos: solo así podía trabajar para la idea de que el Estado debía fundarse en una identidad nacional (Iggers, 2012: 52-57). Así que el trabajo se desarrolla en dos niveles: el de las fuentes y el de la narración.

La tesis de la neutralidad del historiador parece que no fue implícitamente asumida en los orígenes de la historiografía en Inglaterra o Francia, de la que surgió la llamada interpretación whig de la historia, la cual juzga los hechos del pasado desde el metro de un presente en progreso. Por su parte, el marxismo no renunció a la motivación política porque el materialismo histórico se presentaba como un modo de investigación del pasado que servía de herramienta para transformar el presente y proyectar un futuro igualitario.

Marx reconoció explícitamente el ser social de toda conciencia. No obstante, el modelo empirista o historicista se impuso académicamente a comienzos del siglo XX en un contexto de creación y expansión de las áreas académicas dedicadas a las ciencias humanas a las que había que legitimar como tales, dada la necesidad de consolidar un campo profesional. Eso se hizo tomando a las ciencias naturales como modelo, iniciándose la larga controversia entre la cultura científica y la humanista. 
El primer gran debate importante fue la Methodenstreit, es decir, el debate acerca del método apropiado para las ciencias sociales. Desde el momento en el que las acciones humanas responden a una intencionalidad y están orientadas tanto por determinantes internos como externos, requieren que sus análisis impliquen una interpretación, siendo el neokantismo de la escuela de Baden el principal exponente del problema acerca del método a seguir para que puedan legitimarse como ciencias empíricas independientes. Ahí residió el esfuerzo de Wilhelm Dilthey de establecer un campo propio e independiente del modelo naturalista ya que no era posible anular al sujeto.

Tras la Gran Guerra (1914-1918), la llamada escuela de Annales fundada por Marc Bloch y Lucien Febvre amplió el ámbito de estudio de la historia más allá de la historia política o militar practicada en el siglo anterior, sentando las bases temáticas y los ejes de la moderna historiografía, aunque sus enfoques no se popularizaron hasta después de la segunda guerra mundial. Hasta entonces, había sido una exigencia al menos formal que la trayectoria intelectual y la trayectoria vital se mantuvieran separadas, dominando el ideal rankeano de la neutralidad ideológica, aunque se hubieran transformado los intereses y los enfoques de estudio. Sin embargo, después de 1945, cuando desde Francia se irradió la figura del intelectual de izquierdas, surgió una valoración explícita de la persona historiadora como militante, especialmente cuando, a partir de los años sesenta, eclosionaron los movimientos sociales y apareció la llamada historia desde abajo y de la gente pequeña, es decir, aquella que daba voz a los marginados, a las mujeres y, en definitiva, a los olvidados por las historias oficiales. Era también el contexto de surgimiento de la historiografía marxista inglesa de la mano de Christopher Hill o Hobsbawm, a los que se sumó Edward P. Thompson entre otros (Iggers, 2012: 129-191). Desde entonces, el transcurso de la historia como ciencia se ha visto marcado por un pluralismo metodológico y una apertura hacia otras fuentes al margen del archivo (oralidad, arte, literatura, etc.), lo cual, a ojos de algunos, ha situado a la disciplina al borde de un acantilado, pues las fronteras académicas respecto a otras disciplinas, como la antropología, la historia económica o los estudios culturales, cada vez son más difusas. Posiblemente y en este contexto, ha sido a partir de la llamada querella de los historiadores llevada a cabo en Alemania entre los años 1986 y 1987 y las problemáticas asociadas a lo que Jürgen Habermas llamó el uso público de la historia (Habermas, 2007: 77-84), así como los posteriores debates acerca de la memoria histórica, el negacionismo o el revisionismo historiográfico lo que, junto a la cuestión nacionalista, más ha puesto de relieve la tensión entre neutralidad política y objetividad científica. 


\section{CÍRCULO DE LA INTERPRETACIÓN Y POSHISTORIA}

El debate sobre la posibilidad o imposibilidad de separar la subjetividad de la objetividad durante los procesos cognitivos es antiguo y conocido en el campo filosófico, aunque con poco calado en el habitus académico historiador. Desde la tradición de la hermenéutica filosófica se puso de relieve que toda presentación de hechos es siempre una interpretación. La pregunta aquí sería acerca de si el sentido de una serie de acciones humanas del pasado sería un hallazgo por parte de la persona que investiga o una posición de esta como intérprete de unas fuentes que tendría entre sus condicionantes su universo de valores o su cultura política, algo que se ha defendido desde la llamada poshistoria.

Ya se ha dicho que el historicismo de la escuela histórica de Ranke nació en oposición a la filosofía de la historia hegeliana, proponiéndose observar y comprender lo histórico en su concreción sin rendir cuentas a teleologías ni a leyes generales. Eso la conectaba con la pretensión positivista de considerar lo histórico desde la perspectiva naturalista, es decir, como una sucesión de hechos ordenados en el tiempo. Desde ese momento quedaban abiertos tres posibles caminos: la ilusión de la transparencia del descriptivismo rankeano, el dogmatismo de quien encuentra leyes o regularidades históricas (como Oswald Spengler o la historiografía ortodoxa marxista) o el pensamiento débil del relativismo, presente en nuestro tiempo de posverdad bajo la forma del pluralismo metodológico y la permeabilidad hacia otras disciplinas. Veremos en las conclusiones que la virtud profesional en base a un término medio puede encontrar senderos entre ellos. En este y los siguientes apartados se expondrán más bien sus dificultades.

El intento de Dilthey de dotar de fundamento científico a las humanidades en su Introducción a las ciencias del espíritu (1883/1949) aportó el concepto de círculo hermenéutico. Para la interpretación de las acciones humanas no se puede aplicar ni un ideal deductivo lineal que se limite a deducir consecuencias de unas premisas dadas ni otro inductivo que establezca explicaciones a partir de una base observacional, ya que todo sujeto interpreta tal base o aquellas premisas desde una comprensión previa o tradición. Esa precomprensión que orienta la interpretación no sería un defecto del procedimiento de las ciencias humanas que las sitúa epistemológicamente por debajo de las naturales, sino, más bien, una descripción de la estructura misma del comprender (Gadamer, 1992b: 320). Los problemas de la interpretación de la historia son muchos: no solo se trata de traducir para el presente unas lenguas (y, por tanto, estructuras 
mentales y categorías) de otro tiempo y, normalmente, lugar, sino que la precomprensión misma es una condición necesaria de toda interpretación del mundo. Es decir, sin prejuicios y preconceptos, el trabajo histórico no sería posible porque no habría sujeto que lo elaborase.

La crítica de la razón histórica de Dilthey enlazó con la filosofía de Martin Heidegger. Su analítica transcendental del ser-ahí consolidó la idea del círculo hermenéutico de toda comprensión. Comprender no es una operación entre otras del pensamiento humano que los historiadores pueden elegir (frente al deducir o el inducir) como una opción metodológica más, sino que constituye el movimiento básico de ser en el mundo. Quien se enfrenta al conocimiento del pasado está ya en una precomprensión (siempre lingüística) que le posibilita realizar esas operaciones y abrir horizontes de sentido.

Tratando de superar el historicismo y sin caer en el relativismo con el que a veces se le ha asociado, Hans Georg Gadamer hizo de esto una metodología propia para el ámbito de las ciencias humanas y, especialmente, para el arte, tematizando otra forma de verdad diferente a la que opera en las ciencias naturales. Gadamer consideró que Dilthey, en su intento por salvar la honorabilidad de las ciencias del espíritu en un contexto de hegemonía del paradigma naturalista, quedó preso del ideal de una comprensión sin supuestos, que haría de la interpretación de la historia una experiencia ahistórica (Gadamer, 1992a: 282-304). Sin exponer aquí todas las derivas y los debates suscitados por la hermenéutica filosófica, se puede llevar este modelo basado en la experiencia estética al terreno de la experiencia histórica y pensar si el conocimiento del pasado solo se torna valioso o despierta interés si es capaz de introducir modificaciones en el curso histórico de los receptores presentes. Es decir, si se le otorga una función social que vaya más allá de la mera transmisión de datos e informaciones. Igualmente, el modelo hermenéutico conlleva reconocer que se estaría ante un objeto, el pasado, que nunca se puede comprender del todo ya que ha dejado de ser real. En eso, la hermenéutica filosófica se da la mano con la posmodernidad y su puesta en cuestión del logocentrismo occidental, lo cual ha tenido enormes repercusiones para el intento de seguir legitimando la tarea historiadora desde el paradigma rankeano.

Para Gianni Vattimo, la herencia de los siglos XIX y XX ha sido la de la «negación de estructuras estables del ser, a las cuales el pensamiento debía de atenerse para fundarse en certezas que no sean precarias» (Vattimo, 1995: 11). Más que de era posmoderna hay que hablar de una vida poshistórica, pues el transcurso de la historia ha perdido su unidad, bien porque ha desvelado su carácter ideológico, bien porque se ha convertido en narración y en una historia 
(Vattimo, 1995: 16-18). La ciencia histórica no solo estudia hechos en tanto que objetos pensados como prestos a una descripción exhaustiva, sino sujetos que sienten, desean y actúan inmersos en una experiencia vital intraducible de forma transparente por el lenguaje. Así, la experiencia del pasado se torna inagotable y no acotable mediante conceptos. Más bien, como dijo Gadamer, parece que la historia debe escribirse de nuevo desde cada presente, porque siempre tendrá otras experiencias de sentido que transmitir.

Dentro del enfoque posmoderno, en el campo historiográfico destacó la propuesta de Hayden White en su obra ya clásica Metahistory (1973). Para este, la necesidad de estrategias lingüísticas para construir la narración a partir de los datos recogidos durante la investigación la convierten en un acto poético, ficcional, pues el pensamiento está cautivo de la lengua en aquellos campos que no pueden adquirir el estatus de una ciencia elevada (White, 1992: 10-18). Dentro de las diferentes maneras de construcción de la narración histórica (por ejemplo, el tipo de trama por el que se opta; en Ranke, la comedia), se encuentra la explicación por implicacion ideológica. En las dimensiones ideológicas del relato histórico se refleja el elemento ético de la toma de posición de la persona que lo escribe respecto a su visión particular de la naturaleza del conocimiento y de los efectos que tiene este en la comprensión del presente. Hay posiciones metapolíticas que no necesariamente se mantienen conscientemente, pues pueden limitarse a una idea de cómo debe ser la historia en la que late la orientación política a la que dicha idea se debe (liberal, conservadora, anarquista, etc.) (White, 1992: 32-34).

En la propia forma de entender la historia subyacen elementos metahistóricos que difícilmente se pueden neutralizar, tal y como por ejemplo ha puesto de relieve todo el debate acerca de la historiografía sobre el colonialismo, donde se ha señalado cómo la idea de progreso o numerosos elementos etnocéntricos subyacían en la misma. Incluso la denuncia más radical de Occidente, como fue la llevada a cabo por Frantz Fanon, estaba escrita en el elegante estilo de Sartre: Occidente produjo la mayor parte del colonialismo moderno, pero también configura la mayoría de sus interpretaciones (Nandy, 2021: 31).

Las implicaciones del fetichismo de lo real puesto de relieve por White fueron desarrolladas por Hans Kellner o Franklin Rudolf Ankersmit. Si el primero denunció el autoritarismo de nociones como verdad o realidad (Iggers, 2012: 33), el segundo señaló que las propuestas historiográficas no son respecto a cómo fue el pasado, algo imposible de narrar, sino sobre cómo deberíamos verlo, lo cual conlleva, además de una interpretación, intenciones estéticas e ideológicas (Bolaños, 2011). 


\section{HISTORIA Y JUICIOS DE VALOR. UN VIEJO DEBATE EN CIENCIAS SOCIALES}

Para dilucidar la cuestión de la posibilidad o imposibilidad de la imparcialidad política y el papel que las posiciones ideológicas desempeñan en la propia construcción del relato histórico, es interesante recordar un debate que atravesó el campo de la sociología durante buena parte del siglo XX. Este tuvo en su centro el postulado de Max Weber de la eliminación de los juicios de valor como una condición necesaria para que un trabajo de ciencia social pueda considerarse como tal (Weber, 2010).

Unos años antes, en 1911, Émile Durkheim había disertado sobre la diferencia entre juicios de realidad y juicios de valor (Durkheim, 2006: 83-101). Los juicios de realidad son aquellos que remiten a hechos, es decir, son juicios de existencia, del tipo «la hierba es verde». A veces, se emiten juicios de realidad que pasan o se confunden con juicios de valor. Eso ocurre con apreciaciones o preferencias personales del tipo «me gusta el verdor de la hierba». En realidad, son juicios de realidad también, porque remiten a algo que pasa en el mundo (la relación entre un hecho y la valoración que hace el sujeto). En cambio, los juicios de valor son los que atribuyen un valor objetivo a una cosa: «la hierba verde es lo más bello del mundo». No son juicios que hagan referencia a un estado del sujeto en relación a una cosa, sino que sitúan dicho valor, negativo o positivo, en la cosa misma al margen de su relación con el sujeto. Así, llevando la distinción a cuestiones históricas, habría que diferenciar entre un juicio de realidad, del tipo «el teniente coronel Casado formó parte de la organización de un golpe de Estado contra el gobierno de Negrín» (pues lo confirman las fuentes) $\mathrm{o}$ «Pienso que Casado se equivocó porque la guerra aún podía ganarse» (que seguiría siendo un juicio de realidad), y otro del tipo «La acción del teniente coronel Casado contra el gobierno de Negrín fue un acto de cobardía», porque en este caso atribuye a la acción de Casado un valor basado en una realidad que pretende ser objetiva y que es muy difícil de contrastar. Los juicios de valor quedarían para la vida privada o pública del investigador o para sus lectores, pero al margen de la exposición de su trabajo científico.

Para Weber son este tipo de valoraciones y modos de prejuzgar los que deben quedar al margen de las ciencias sociales, proclamando la neutralidad axiológica e intentando alejar las cuestiones políticas de las científicas. Una influencia importante, el neokantiano Heinrich Rickert, llevó a cabo una serie de críticas al ideal de la transparencia de Ranke. Para Rickert esta no era posible totalmente desde el momento en que es el sujeto historiador quien selec- 
ciona su objeto de estudio pues, ¿desde qué posición o valoración lo hace? Si este apagara su yo (Rickert, 1942: 141), el resultado de su estudio sería realmente incomprensible, al no establecer un orden o una jerarquización en términos de importancia en sus análisis y procesamiento de las fuentes o una organización expositiva de lo que se quiere narrar.

¿Cómo se procesan datos o se construye un texto sin estimaciones de importancia respecto a la información que se recolecta? ¿Sería tarea historiadora limitarse a exponer tablas de conjuntos de datos inconexos? Aun así, ¿la clasificación de las mismas estaría libre de subjetividad? Presuponer una objetividad total supondría que todo resultado sería intercambiable, de tal modo que los libros de historia podrían prescindir de la autoría como lo pueden hacer las constantes en física. Sin embargo, no solo forma parte de la atracción de los lectores el estilo narrativo propio, sino que la tarea historiadora sería imposible sin una valoración previa de lo que a la persona que investiga le interesa investigar, que acota el objeto consciente o inconscientemente. Y, si no se jerarquiza en importancia lo estudiado, será extraño que el resultado sea inteligible para sus lectores. Ahí reside la pertinencia de la distinción de Durkheim, pues la crítica de Rickert salva los juicios de realidad que suponen estimaciones personales, del tipo: «me resulta más importante, en la estimación de la represión franquista y su orden de exposición al público, los fusilados por bando o consejo de guerra que los muertos por tifus en la cárcel en una ciudad determinada». Se dejan aparte los juicios de valor propiamente dichos. Aun así, también para Weber, los valores tenían una función fundamental: orientar la investigación, seleccionar temáticas, ordenar resultados... Pero ¿es posible la asepsia ideológica que postulaba? ¿Y por qué esta sería más deseable?

Para Durkheim los valores no estarían objetivamente en las cosas o en los hechos, sino que vienen determinados por el colectivo social al que pertenece quien los enuncia. La significación respecto a un hecho social depende de un aparato conceptual previo y, a veces, inconsciente, el cual predispone el enfoque teórico, esto es, la gama de conceptos que vamos a aplicar a la interpretación de los hechos y la terminología para narrarlos. Así, en el ejemplo anterior, hay quien cambiaría represión por violencia política, edulcorando la primera, o muertos por tifus por muertos por hambre, tal y como parece que ocurrió en muchos casos y se acerca más a la verdad (a pesar de lo que reza en los documentos de prisiones). Por ello es problemático defender que los términos o las categorías de análisis historiográfico son políticamente neutros. Sobre ello llamó la atención Robert K. Merton (2003: 544-545, 617-618). Cuando, por ejemplo, se usa el término delincuencia para clasificar el conjunto de hechos delictivos de 
las clases populares, pero se elude para la conducta de un rey; cuando se usa el de biopolítica para analizar procesos de gobierno de las poblaciones en la Prusia de Federico II o el de bando nacional para hacer referencia a los sublevados contra la Segunda República, ¿se está haciendo un uso aséptico de los mismos o esconden una predisposición ideológica previa? ¿Se apaga el yo para elegir estudiar la marginalidad gitana en la Sevilla del siglo XVIII en lugar de sus arzobispos?

Fontana recordaba la queja de Thompson sobre cierto revisionismo que cambiaba términos como feudal, capitalista, burgués o patriarcal por otros como preindustrial, modernización o paternal (Fontana, 1992: 79-80; Thompson, 1995: 32-33) y se resistió a abandonar, reformulándolo, el concepto de clase. Los condicionantes ideológicos parecen claros tanto en él como en los otros, pero no se pueden obviar las determinaciones inconscientes de otros campos sociales que, comenzando por el académico, se ejercen sobre los agentes investigadores, tal y como ha puesto de relieve la sociología intelectual de Pierre Bourdieu. Dichas determinaciones no se dan directamente, sino mediadas por las propias estructuras (repartidas especialmente en la división dominantes/dominados) del campo y los intereses del individuo con su propia subjetividad. Tampoco hay que olvidarse de la posición del campo en el que trabaja res-pecto al campo de poder y de las injerencias políticas o económicas (con-tratos, subvenciones, becas, etc.) externas a la investigación. Las estructuras del campo académico en sí, como puedan ser las formas de progreso profesional en la universidad y las relaciones de poder que constituyen sus departamentos, crean un habitus o conjunto de disposiciones en dos sentidos: por una parte, estructuras mentales desde las que se eligen temas de estudio, se adoptan términos, se recolectan datos, se los interpreta y expone y, por otra, disposición corporal a actuar de un modo determinado ante los demás según su posición relativa en el campo de poder. Así, quienes trabajan en un ámbito profesional determinado tienden a asumir como naturales los esquemas de pensamiento, los problemas o los intereses de estudio previamente establecidos, en definitiva, «el sistema de supuestos que está ligado a la clase intelectual como grupo de referencia privilegiado» (Bourdieu, Chamboredon y Passeron, 2002: 105). Igualmente, el espacio académico se constituye de subespacios (áreas, materias...) que se reproducen como espacios sagrados a través de rituales de interacción y vigilancia de fronteras frente a áreas vecinas consideradas como profanas: eso redunda en la necesidad de afianzar una terminología propia que diferencie a una ciencia social de la otra (o de la propia filosofía) y la legitime como campo profesional independiente frente a otros. 
El cuestionamiento de los preconceptos es una exigencia epistemológica que todo buen profesional de la historia tiene en cuenta. Someter a revisión las categorías de análisis, cambiarlas por otras consideradas más adecuadas o ser consciente de la incapacidad de las mismas para abarcar la totalidad de lo pasado es una demanda interna del propio trabajo de investigación y divulgación, ¿pero no lo es también la ética? Se terminará de examinar más adelante. Por ahora, solo recordar que el principio de neutralidad axiológica promulgado por Weber como dogma asumido por los enfoques metodológicos en las ciencias sociales fácilmente incorporable a códigos éticos o de buenas prácticas puede incitar en sus formas rutinarias a cometer los errores epistemológicos y los fallos morales que aspira a prevenir porque, entre otras operaciones, bajo su valor simbólico puede enmascarar motivaciones ideológicas menos explícitas. Es más, el imperativo ético de la neutralidad corre el peligro de funcionar más como fórmula ritual en la constitución de fronteras académicas y de justificación de carreras profesionales o editoriales que como autoexigencia moral y epistemológica real. Por ello, la asimilación de una ética del campo en cuestión contribuye de forma honesta a legitimar e identificar al cuerpo profesional que lo trabaja.

\section{UN ESTUDIO DE CASO}

El historiador Manuel Álvarez Tardío publicó en el 2016 un artículo dedicado a las intimidaciones a las que se pueden ver sometidos quienes se acercan al estudio de la Segunda República española por parte de algunos círculos historiográficos. Desde su óptica, la hegemonía del enfoque de izquierdas implica una serie de coerciones de origen ideológico para los investigadores que se acercan a dicho periodo, de tal modo que resultan sospechosos de falta de calidad o de imparcialidad quienes tienen algún vínculo con partidos o instituciones de derecha, pero no ocurre igual si se es un destacado militante de izquierdas. Así, desde dicha hegemonía historiográfica de izquierdas en el estudio de aquel periodo, se usa el término revisionista en sentido peyorativo, como forma de historia neofranquista. Pero, bajo las rúbricas de la defensa de la verdad y la justicia, la acusación esconde un modo de inquisición y de blindaje de círculos intelectuales y académicos de izquierda. En ese sentido, señala la excesiva presencia de la dicotomía fascismo-antifascismo a la hora de interpretar el periodo, pues impide entender la lógica de partidos - y la lógica de la propia sociedad - antes y después de febrero de 1936 (Álvarez, 2016). 
La denuncia de este historiador podría ser un caso de lo que Miranda Fricker ha llamado injusticia epistémica y, más en concreto, de injusticia testimonial, que se produce cuando los prejuicios adquiridos socialmente de un oyente le condicionan para que el discurso del hablante llegue disminuido o minusvalorado desde el punto de vista de su veracidad (Fricker, 2017: 17-18). Así, en un tiempo de polarización política como el nuestro, dicho tipo de injusticia estaría ampliamente extendida: el juicio sobre el grado de veracidad de un discurso o texto está condicionado por la vinculación que tenga su autoría con una determinada ideología, unas instituciones o una familia política y no se mediría únicamente por su verificabilidad con las fuentes.

Colaborador en publicaciones de la FAES o de Libertad Digital y profesor en la Universidad Rey Juan Carlos, Álvarez Tardío ha destacado en los últimos años por su renovación del estudio de la figura de José María Gil Robles, pero, sobre todo, por la publicación junto a Roberto Villa del libro 1936: Fraude y violencia en las elecciones del Frente Popular (2017). La publicación de esta obra desató una larga serie de reacciones y contestaciones que, analizadas con distancia, constituyen un interesante caso de estudio tanto de epistemología de las ciencias sociales como de ética de la investigación, pues protagonizó el debate historiográfico durante meses y saltó a la batalla cultural de la política, como se comprueba con una simple búsqueda en la red.

Reivindicando y haciendo gala de objetividad histórica y de uso de una amplia base empírica frente a la interpretación ideológicamente instituida de aquellas elecciones, los autores demostraron que, en algunas circunscripciones, se habían manipulado las actas electorales sin que eso implicase luego un resultado significativamente distinto. Rápidamente, las redes sociales y los partidos políticos de derechas se avinieron a hablar de "pucherazo del 36», deslegitimando así al gobierno del Frente Popular presidido por Manuel Azaña. Como ya se sabe, esa acusación de ilegitimidad fue una de las primeras justificaciones que el franquismo hizo del fallido golpe militar que trajo consigo la guerra civil. De ese modo, el libro fue aplaudido por la extrema derecha, desde Hermann Tertsch y Federico Jiménez Losantos hasta la Fundación Francisco Franco. Sin embargo, los mismos autores niegan en su obra que se pueda cuestionar la legitimidad del gobierno del Frente Popular (2017: 380, 517), a pesar del título (fraude y violencia) o a que el capítulo 8 se titule « ¿Una victoria del Frente Popular?».

Unos años antes, los historiadores Stanley Payne y Jesús Palacios (2014) habían planteado algunos interrogantes sobre la legalidad del gobierno republicano en una biografía política sobre Franco que presentaron como definiti- 
va y que motivó una contestación por parte de un grupo de historiadores en un número colectivo de Historia Nova coordinado por Ángel Viñas (2015). De ese modo, $1936 \ldots$ era un libro recibido en el seno de un debate ya preexistente que vino a situar a sus autores, a ojos de historiadores como Francisco Espinosa, en el marco de una segunda ola del revisionismo neofranquista que, a diferencia de la de los años noventa (que protagonizaron Pío Moa y César Vidal), ahora se encontraría dentro de lo académico: revisionismo porque los hechos se reinterpretan para distorsionarlos con una intención política. Para Espinosa, trayectorias así son ejemplos de «absorción de las tesis revisionistas desde el seno de la Universidad» (2019).

Ya hablamos en el apartado anterior de la elección de términos y de la exigencia doblemente ética y epistemológica de cuestionar los mismos, sobre todo cuando aparecen en el título de una obra de la que se pueden anticipar las reacciones. Moradiellos (2017), en un minucioso y desapasionado comentario del libro, de las elecciones y de la polémica, analizó la organización y el diseño del título basándose en instrumentos semióticos. 1936 aparece en tamaño grande y rojo; fraude y violencia, en tamaño medio en mayúsculas y en negro, mientras que en las elecciones del Frente Popular aparece en menor tamaño y minúscula. Obviamente, las connotaciones del título son evidentes: las elecciones quedan vinculadas al fraude y a la violencia y, como tal, favorece las tesis revisionistas y la visión dominante en la derecha española. Lo dicho, dejando al margen una arista que conduciría a la ética profesional de las editoriales, nos lleva a ejemplificar lo explicado en el apartado anterior: la llamada a la objetividad y la neutralidad axiológica puede nublar motivaciones ideológicas reales o, al menos, eludir la necesaria autocrítica ética y epistemología sobre los términos empleados. Doble responsabilidad en un contexto de creciente polarización política. Por su parte, Espinosa, en el artículo citado, también acusa a Moradiellos de edulcorar lo sucedido en su Historia mínima de la Guerra Civil española (2016) al hablar de violencia aplicada respecto a la represión y la estrategia del terror por parte del ejército sublevado o de orientación fascistizante en lugar de fascismo para referirse al franquismo.

A problemáticas no menores conducen las llamadas a la equidistancia a la hora de estudiar la guerra civil, la posguerra, los cuarenta años de dictadura militar franquista o los años de plomo de la transición. Tal llamada transmite la idea de una tercera España víctima de las otras dos, que quedarían igualadas en responsabilidad sobre desastres que no parecen provocados por sujetos responsables sino por una especie de irracionalidad patria. Por ello, Francisco Moreno Gómez señala que la llamada a la equidistancia o a la neutralidad «es 
la posición más ideologizada que existe» (Moreno, 2014: 52). Evitar los juicios de valor sobre los agresores, los verdugos y los vencedores de la guerra civil supone renunciar a influir en una memoria que aún hoy viene legitimando la dictadura militar franquista, que mantiene una leyenda rosa de la transición y de una democracia que se ha olvidado de los cuerpos de sus víctimas y de sus familiares hasta tiempos muy recientes. En ese sentido, para este historiador, llamar a la equidistancia o enarbolar la bandera de la objetividad puede esconder un afán militante, si no en la derecha, al menos sí en las agencias de evaluación académica. Pero Moreno Gómez también ha sido objeto de críticas por tildar a la matanza llevada a cabo por las fuerzas sublevadas en Córdoba de genocidio en su libro más conocido, siendo acusado de falta de reflexión conceptual y de empleo acrítico y militante (Míguez, 2012). Dado que la represión franquista se ejerció fundamentalmente por motivos políticos y de estrategia militar y no por motivos étnicos, no cabe hablar de genocidio. Así, el introducir el vocablo genocida en un título como El genocidio franquista en Córdoba (2008) buscaría los mismos efectos que el título de Álvarez Tardío y Villa, aunque sobre un público con predisposiciones ideológicas distintas.

\section{CONCLUSIÓN ABIERTA}

A lo largo de este trabajo se ha intentado profundizar en la imposibilidad de negarse como sujeto político durante la investigación y la narración históricas. Desde ahí, se trataría ahora de esbozar una orientación para el análisis ético que se haga cargo de la misma y que, en este trabajo, se ha centrado en los presupuestos ideológicos (en un sentido político) que se esconden mejor o peor en la terminología usada por los historiadores. Esa es una de las sendas por las que la exigencia ética puede enriquecer la autocrítica epistemológica.

Frente a la ilusión de la transparencia, parece que no existe un terreno neutro a partir del cual se elige tomar o no partido, porque no hay sujeto sin lugar donde este esté posicionado más allá de la imaginación (Jenkins, 2009: 70-71). Por eso, se toma partido tomándolo explícitamente, pero también negando que se toma en beneficio de la objetividad, especialmente cuando se trabaja sobre acontecimientos que generaron y generan dolor. Por tanto, puede ser una mejor praxis profesional no ocultar las preferencias y los valores personales, siempre y cuando estos no enturbien ni falseen la evidencia de las fuentes. En ese sentido, puede ser útil la distinción de Durkheim entre valoraciones personales (que serían juicios de realidad) y de juicios de valor, que ex- 
presan una verdad fuera del sujeto: mientras que los primeros son de esperar, al menos en las conclusiones, los segundos estarían legitimados — eso no significa que no sean prescindibles en una narración- si las fuentes así lo apoyan.

Un problema de la historia durante su proceso de institucionalización como disciplina académica radicó en considerarse una ciencia dominada respecto a las ciencias naturales en lugar de delimitarse en su propia especificidad no solo metodológica, sino desde el punto de vista de la teoría de la verdad en la que se manejaba. A diferencia de aquellas, el saber en las ciencias humanas raramente funciona en el marco de una teoría de la adecuación o correspondencia con lo real, porque lo que estudia ya no tiene realidad. Eso no significa que no queden criterios para evaluar la calidad de una producción historiográfica en estos tiempos de poshistoria. A diferencia de las ciencias naturales, la historia sería un saber de participación y de formación humanista donde se adquieren explicaciones del pasado por procedimientos científicos y donde estas constituyen experiencias de sentido que ayudan a leer el presente.

Como se ha dicho, la ausencia de compromiso parece ya ideológica, especialmente si entramos en el terreno de la historia contemporánea y en la explicación de acontecimientos traumáticos. La ciencia histórica debe tener en cuenta una serie de principios: el de la verificabilidad de las pruebas o fuentes, el del desarrollo inmanente (es decir, racional y no providencial o teleológico) del devenir histórico y la ordenación y significación temporal (Moradiellos, 1994: 10-22). A partir de este punto, podríamos elegir tres modelos o perspectivas para evaluar éticamente un texto historiográfico, seamos o no los responsables de su autoría. El primero sería formal y se centraría en el mero contenido del texto, evaluándolo en función de la objetividad que presente, por lo que la parcialidad sería signo de falta de rigor científico, siendo este el modelo al que aspira la tarea historiadora bajo el ideal rankeano. Otra opción puede ser considerar la posición personal como parte de la propia obra, la cual enriquecería la misma, pues el resultado no hubiese sido así sin una motivación ideológica declarada. Tal impronta personal sería también objeto de interés historiográfico y podríamos acordarnos, sin más, de las interpretaciones de Marx del ciclo revolucionario francés. En tercer lugar, estaría una reflexión ética que evaluase tanto la veracidad de la obra como la proyección en la misma de la posición personal desde la honestidad intelectual, lo que obliga a juicios de valor bien fundados. Es decir, no negándola ni ocultándola ni tampoco pensando que la enriquece necesariamente, porque su efecto puede ser distorsionador. Respecto a esto último, cabe recordar que tomar partido por los derechos humanos no está reñido con la objetividad en la descripción de lo ocurri- 
do. Esta tercera opción es la que pensamos como más propicia para el desarrollo de la virtud (areté), que convierte la producción académica en praxis histórica, es decir, aquel tipo de acción que tiene un valor inmanente independientemente del beneficio obtenido y que es el principal signo de excelencia profesional (Camps, 1990: 117). Es ahí donde debería residir el valor distintivo de las humanidades: en el hecho de ser un fin en sí, una búsqueda del saber que directamente conlleva la función social de formar ciudadanos críticos y con una conciencia histórica en la que se reconozca que el pasado es complejo y plural y no algo que sirva (primeramente) para otra cosa, sea una carrera profesional, una institución o una ensoñación política.

\section{BIBLIOGRAFÍA}

Allier Montaño, Eugenia (2011). Ética y política en el historiador del tiempo presente. Teoría de la Historia, vol. 1 (151-171). México D. F.: Universidad Iberoamericana.

Álvarez Tardío, Manuel (2016). La política, la intimidación y la historia de la Segunda República. Cuadernos de pensamiento político FAES, $51,1-8$.

Álvarez Tardío, Manuel y Villa García, Roberto (2017). 1936: Fraude y violencia en las elecciones del Frente Popular. Madrid: Espasa.

Beauchamp, Tom L., Faden, Ruth R., Wallace, R. Jay y Walters, Jr. Leroy (eds.) (1982). Ethical Issues in Social Science Research. Baltimore: Johns Hopkins University Press.

Bolaños de Miguel, Aitor Manuel (2011). Historiografía y postmodernidad. La teoría de la representación de F. R. Ankersmit. Historia y Política, 25, 271-308.

Bourdieu, Pierre, Chamboredon, Jean-Claude y Passeron, Jean Claude (2002). El oficio de sociólogo. Presupuestos epistemológicos. Buenos Aires: Siglo XXI.

Camps, Victoria (1990). Virtudes públicas. Madrid: Espasa.

Canal, Jordi (2015). Historia mínima de Cataluña. Madrid: Turner.

Carr, David, Flynn, Thomas Robert y Makkreel, Rudolf A. (2004). The Ethics of History. Evanston: Northwestern University Press. 
Demicheli, Tulio (2012). Juicio a la objetividad del historiador. $A B C, 7$ de octubre de 2012.

Dilthey, Wilhelm (1883/1949). Introducción a las ciencias del espíritu. Buenos Aires: F. C. E.

Durkheim, Émile (2006). Sociología y Filosofía. Granada: Comares.

Espinosa, Francisco (2019). El revisionismo en perspectiva: de la FAES a la Academia. Recuperado de https://conversacionsobrehistoria.info/ 2019/og/14/el-revisionismo-en-perspectiva-de-la-faes-a-la-academia/ [Consultado el 15 de julio de 2020].

Fontana, Josep (1982). Historia. Análisis del pasado y proyecto social. Barcelona: Crítica.

Fontana, Josep (1992). La historia después del fin de la historia. Barcelona: Crítica.

Fricker, Miranda (2017). Injusticia epistémica. Barcelona: Herder.

Gadamer, Hans Georg (1992a). Verdad y método I. Salamanca: Sígueme.

Gadamer, Hans Georg (1992b). Verdad y método II. Salamanca: Sígueme.

Habermas, Jürgen (2007). Del uso público de la historia. La quiebra de la visión oficial de la República Federal de Alemania. Pasajes: Revista de pensamiento contemporáneo, 24, 77-84.

Iggers, Georg G. (2012). La historiografía del siglo XX. Desde la objetividad científica al desafío posmoderno. Santiago de Chile: Fondo de Cultura Económica.

Jenkins, Keith (2009). Repensar la Historia. Madrid: Siglo XXI.

Juliá, Santos (2015). Catalanismos: de la protección a la secesión. El País. Recuperado de: https://elpais.com/cultura/2015/o8/27/babeli a/1440676636_155219.html [Consultado el 23 de octubre de 2020].

Lahman, Maria K. (2018). Ethics in Social Science Research: Becoming Culturally Responsive. California: SAGE.

MacIntyre, Stuart y Clark, Anna (2004). The History wars. Melbourne: Melbourne University Publishing.

Merton, Robert K. (2003). Teoría y estructuras sociales. Madrid: Dykinson. Míguez, Antonio (2012). Práctica genocida en España. Discursos, lógicas y memoria (1936-1977). Historia contemporánea, 45, 545-573. 
Moradiellos, Enrique (1994). El oficio de historiador. Madrid: Siglo XXI. Moradiellos, Enrique (2017). Las elecciones generales de febrero de 1936: una reconsideración historiográfica. Recuperado de https://www.re vistadelibros.com/discusion/las-elecciones-generales-de-febrero-de1936una-reconsideracion-historiografica [Consultado el 20 de marzo de 2020].

Moreno Gómez, Francisco (2014). La victoria sangrienta 1939-1945. Un estudio de la gran represión franquista, para el Memorial Democrático de España. Madrid: Alpuerto.

Nandy, Ashis (2021). El enemigo íntimo. Pérdida y recuperación del yo bajo el colonialismo. Madrid: Trotta.

Palacios, Jesús y Payne, Stanley (2014). Franco. Una biografía personal y política. Madrid: Espasa.

Rickert, Heinrich (1942). Ciencia cultural y Ciencia natural. Madrid: Espasa-Calpe.

Thompson, Edward P. (1995). Costumbres en común. Barcelona: Crítica. Tortella, Gabriel (2015). Una historia para catalanes convencidos. Revista de libros. Recuperado de: https://www.revistadelibros.com/ discusion/una-historia-para-catalanes-convencidos [Consultado el 23 de octubre de 2020].

Vattimo, Gianni (1995). El fin de la modernidad. Nihilismo y Hermenéutica en la cultura posmoderna. Barcelona: Gedisa.

Viñas, Ángel (coord.) (2015). Sin respeto por la Historia. Una biografía de Franco manipuladora. Historia Nova, 1 extraordinario.

Weber, Max (2010). Por qué no se deben hacer juicios de valor en la sociología y en la economía. Madrid: Alianza.

White, Hayden (1992). Metahistoria. La imaginación histórica en la Europa del siglo XIX. México D.F.: Fondo de Cultura Económica.

Wiener, John (2005). Historians in Trouble: Plagiarism, Politics, and Fraud in the Ivory Tower. New York: The New Press. 